\title{
Cytokines in Multiple Sclerosis - Possible Targets for Immune Therapies
}

Anastasiya G. Trenova" and Georgi S. Slavov

Department of Neurology, Medical University - Plovdiv, Bulgaria

Correspondence to:

Anastasiya G. Trenova, PhD

Department of Neurology

Medical University-Plovdiv, 15a "Vasil Aprilov" Str

Plovdiv 4000, Bulgaria

Tel: +35932602205

E-mail: atrenova@yahoo.com

Received: November 10, 2015

Accepted: January 11, 2016

Published: January 14, 2016

Citation: Trenova AG, Slavov GS. 2016. Cytokines in Multiple Sclerosis - Possible Targets for Immune Therapies. J Neurol Exp Neurosci 1(2): 25-29.

Copyright: (C) 2016 Trenova and Slavov. This is an Open Access article distributed under the terms of the Creative Commons Attribution 4.0 International License (CC-BY) (http:// creativecommons.org/licenses/by/4.0/) which permits commercial use, including reproduction, adaptation, and distribution of the article provided the original author and source are credited.

Published by United Scientific Group

\begin{abstract}
The complex interactions between the central nervous system and the immune system are mainly mediated via synthesis and secretion of cytokines. Disturbance of the fine balance between different cytokine subpopulations is undeniable factor in the development of pathological process in multiple sclerosis. Experimental and clinical studies examining the impact of individual cytokines on the course of the disease often give conflicting results. The reason for this may be searched in the complex interactions within the cytokine network, dependent on the local milieu in the central nervous system. Efforts to modulate autoimmune process in multiple sclerosis have shown that effective treatments alter cytokine expression in a favorable way, indicating cytokines as possible therapeutic targets. The widely approved disease modifying treatments with interferon-beta, glatiramer acetate, cytostatic drugs, but also experimental therapeutic agents like estriol, statins and vitamin $\mathrm{D}$ have been proved to exert their beneficial effect partially by impact on different aspects of cytokine production. The purpose of this review is to highlight the importance to consider the complexity of cytokine interactions in pathogenesis and treatment of multiple sclerosis. Increase of the knowledge in this area will create opportunities for more precise determination of targets for immunologically active drugs in order to improve their effectiveness.
\end{abstract}

\section{Keywords}

Multiple sclerosis, Cytokines, Disease modifying treatment

\section{Introduction}

Multiple sclerosis (MS) is a chronic disease of the central nervous system (CNS) with complex and not fully clarified genetic-environmental interactions playing role in its etiology. These interactions unlock aberrant immune response directed towards myelin antigens in the brain and spinal cord.

The sensitization and first activation of autoreactive CD4 ${ }^{+} \mathrm{T}$ lymphocytes occurs in the peripheral blood. Through series of interactions they pass the bloodbrain barrier and invade the CNS. After second activation and in connection with other immune cells autoreactive $\mathrm{T}$ cells develop pathological process, leading to focal immune demyelination and axonal loss in the brain and spinal cord [1].

\section{Role of Some Cytokines in Experimental Allergic Encephalomyelitis and MS-Pathology}

Cytokines are critical components of the immune inflammatory process and are involved in oligodendrocyte cell death, axonal degeneration and neuronal 
dysfunction which are typical features in MS pathology. They are produced by different types of immune cells including macrophages, natural killer cells, B cells, T-regulatory (Treg), T-helper (Th) and T-cytotixic (Tc) lymphocytes, microglia etc. According to their cytokine production Th cells are divided into several subclasses - Th1, Th2, Th17, Th9 [2]. Autoreactive Th1 type lymphocytes produce IFN-gamma, TNF-alpha, interleukine-2 (IL-2), and are regarded as "encephalitogenic", because transferred into experimental animals can cause experimental allergic encephalomyelitis (EAE) [3]. Increased levels of Th1 cytokines are particularly evident during EAE/ MS relapse, whereas increased Th2 cytokines, such as IL-4 are found during remission in MS patients [4]. However, the imbalance between Th1/Th2 subpopulation is only a part of complex interactions underlying the disease pathogenesis.

Treg cells are essential for the control of the immune responses and the maintenance of immune tolerance [2]. Theories regarding the pathogenesis of autoimmune CNS inflammation assume that there is a disturbed balance between the cells that cause tissue damage and demyelination (effector T cells), and the cells that are capable of suppressing the function of self-reactive $\mathrm{T}$ cells (regulatory $\mathrm{T}$ cells). The proportion of Treg lymphocytes was found decreased in MS patients compared to healthy controls [2]. Recent findings indicate that MS is accompanied by dysfunction or impaired maturation of Treg cells [5].

The later discovered subset Th17 was proved to exacerbate the autoimmune process [2]. The levels of IL-17 produced by myelin basic protein-stimulated peripheral blood cells were shown to correlate with the active lesions in MS patients and microarray studies of MS lesions demonstrated increased IL17 expression [6, 7]. Like other Th subsets, the Th17 lineage is activated by a specific cytokine milieu. IL-23, TGF-beta, IL-6, and IL-1 are required for their generation and IFNgamma decreases the frequency of Th17 peripheral cells and proliferation of Th17 clones in active MS $[8,9]$.

Another recently identified effector subset Th9 can also induce EAE but in a different pathological manner. In the presence of TGF-beta, Th17 cells can produce IL-9. The IL-9 neutralization and IL-9-receptor deficiency attenuated the disease, and this correlated with reductions in Th17 cells and IL-6-producing macrophages in the CNS [10].

On the other side, cytokines such as IL-4, IL-10, TGFbeta, TNF-alpha via TNF-receptor 2, IL-1beta are involved in immune mechanisms that contribute to CNS recovery, protection and repair [11].

This very short overview suggests the pleiotropic properties of the cytokines and the extremely complicated interactions within the cytokine network and between them and the CNS in the development of the pathological process in MS.

Progressive forms of MS are also characterized with some changes in cytokine expression. IL-12 p40 mRNA levels were found increased in unstimulated peripheral blood mononuclear cells (PBMCs) in secondary-progressive patients compared to controls and production of IL-12 p70 by stimulated PBMCs was higher in progressive than in acute forms of MS or controls. Increased expression of IFN-gamma after anti-
CD3 stimulation of PBMCs was reported in patients with secondary-progressive MS compared to relapsing-remitting MS or controls [3]. But in late stages of MS the autoimmune process becomes restricted within the CNS where the immune cells from the so called "lymph nodes", the blood-brain barrier is closed and the degenerative processes with loss of brain tissue become more prominent. For these and other reasons little is known about changes of cytokine interactions within the local milieu.

Efforts to modulate autoimmune process in MS have shown that effective treatment changes different aspects of cytokine production.

\section{Effects of Interferon-Beta on Cytokine Profile}

Interferon-beta-1b (IFN-beta-1b) was the first approved disease-modifying treatment (DMT) for MS. Changes in cytokine synthesis were studied both to understand mechanisms of action and to monitor the therapy (as biomarkers). There are many reports describing specific products regulated by IFN-beta. These include IL-10, IL-12, IL-17F, IL-23, IL-27, etc. [2, 10, 12-14]. The cerebro-spinal fluid (CSF) IL-10 was found increased in MS patients, treated for two years with IFN-beta-1a but not with placebo. Within IFNbeta-treated patients those with increased levels of IL-10 in CSF showed less disability progression [15].

A small study on disability and cytokine secretion revealed interesting results. Patients treated with IFN-beta had significantly lower serum concentrations of IFN-gamma in relapse than the controls unlike those without DMT and lower levels of this pro-inflammatory cytokine correlated with less disability assessed by Expanded Disability Status Scale (EDSS) in the same phase [16]. With respect to the other studied cytokines (TNF-alpha, IL-10, IL-4) data from this study are supportive of the hypothesis of Pellegrini about restoration, to some degree, of the impaired cytokine balance as an effect of IFN-beta therapy [17].

\section{Glatiramer Acetate Treatment and Cytokines}

Glatiramer acetate (GA)-binding to MHC class II molecules on peripheral antigen-presenting cells and subsequent interaction with T-cells leads to induction of GA-specific T-cells. They cross the blood-brain barrier and are reactivated in CNS by the cross-reacting myelin antigens. The reactivated $\mathrm{T}$ cells produce suppression on the immune response against myelin via reducing the expression of proinflammatory and sustaining the stable expression of Th2 anti-inflammatory cytokines (bystander suppression) [18]. Increased secretion of IL-10 and reduced production of IL-12 from monocytes was reported under GA treatment [19]. In humans, GA impairs interactions between activated T-cells and microglia thus suppressing induction of several pro-inflammatory cytokines [20]. CNS infiltration of GAspecific T-cells results in increased expression of IL-4, TGFbeta and IL-10. Similar findings were reported in experimental animal models, suggesting that GA creates non-inflammatory 
cytokine milieu in the CNS [21]. In contrast to IFN-beta treatment, which reduces the expression of IFN-gamma by T-cells, GA-treated patients do not differ in their T-cell expression of IFN-gamma compared to untreated subjects [22].

\section{Effects of Escalating and Target-therapies on Cytokine Production in MS}

Natalizumab, recombinant humanized $\alpha 4$-integrin antibody, blocks migration of lymphocytes into the CNS [23]. Study of Mellergarrd et al. showed marked decline in CSF levels of cytokines and chemokines, thus including proinflammatory cytokines IL-1beta, IL-6 and IL-8. Circulating plasma levels of some cytokines (GM-CSF, TNF-alpha, IL-6 and IL-10) were also found decreased after one year of treatment [24]. Significantly lower serum concentrations of pro-inflammatory cytokines TNF-alpha, IFN-gamma, IL1beta, IL-6, IL-17 and IL-23 were found in natalizumabtreated MS patients compared to drug- naïve or IFN-betatreated ones [25].

Fingolimod, sphingosin-1-phosfate receptor modulator, inhibits egress of autoreactive lymphocytes from lymph nodes and prevents their recirculation in the CNS [26]. Study of Serpero et al. [27] showed that fingolimod functionally modulates the ability of potentially pathogenic effector cells to produce relevant pro-inflammatory cytokines and increases the number of circulating regulatory $\mathrm{T}$ cells possibly contributing in restoring the balance between these subpopulations [27]. There are data that Fingolimod significantly increases the expression of IL-6, IL10 and IL-17A cytokines from PBMCs but other studies show no direct effect on cytokine production $[28,29]$.

Members of the new class MS-treatments are Dimethyl fumarate, Alemtuzumab, Daclizumab, Teriflunomid. For each of them there are evidences about changes in different aspects of cytokine production and interactions.

Clinical trials showed that Dimethyl fumarate (DMF) induces shift from Th1 to Th2 type cytokine secretion with reduced levels of TNF-alpha and IFN-gamma and markedly increased levels of IL-4, IL-5 and IL-10. Similar are the results from experimental studies. In addition, DMF downregulates dendritic cells, which play central role in regulation of the inflammatory processes and suppresses their IL-12 secretion $[30,31]$.

Treatment with Alemtizumab, a monoclonal antibody (Ab) targeting CD25 antigen on the surface of lymphocytes, monocytes, macrophages, natural killer cells, eosinophils, diminishes secretion of all cytokine classes (Th1, Th2 and Th17) after 1 year administration [32].

Daclizumab, another monoclonal $\mathrm{Ab}$, exerts its effect through modulation of IL-2 signaling. IL-2 is crucial for the clonal expansion of autoreactive $\mathrm{CD}^{+} \mathrm{T}$ cells. Binding to the alpha subunit specifically blocks high-affinity IL-2 Receptor but not intermediate-affinity IL-2 Receptor and leads to decrease in $\mathrm{CD}^{+} \mathrm{T}$-cell proliferation and increase in the number of the regulatory natural killer cells [33].

Teriflunomide inhibits proliferation of activated lymphocytes and diminishes the number of activated $\mathrm{T}$ and $\mathrm{B}$ cells that are able to migrate into the CNS. It was shown to decrease the release of IL-6 and IL-8 from human PBMCs. In vitro studies found increased levels of TGF-beta in presence of teriflunomide and lower production of IFN-gamma from myelin basic protein-specific activated $\mathrm{T}$ cell lines [34].

\section{Other Modulators of the Cytokine Production}

Changes in cytokine production are amongst the mechanisms of action of other agents such as statins, Vitamin $\mathrm{D}$ and sex hormones, which are thought to be beneficial in MS.

It is accepted that Vitamin D restores the balance between Th1 and Th2 type cytokine secretion and statins inhibit IFN-gamma inducible expression of MHC class II molecules on microglia and antigen - specific activation of myelin-specific $\mathrm{CD}^{+} \mathrm{T}$ cells, accompanied by reduced secretion of pro-inflammatory Th1 cytokines. Many but not all studies demonstrate that statins may enhance Th2 cytokine production $[35,36]$.

Observations on immune changes during pregnancy and the dramatic reduction of the relapse-rate in the last trimester drew attention on immune-modulatory effects of female sex hormones [37]. A study of our team on hormonal and cytokine secretion in women with MS showed that abnormally low concentrations of sex hormones are associated with higher serum levels of pro-inflammatory cytokines TNF-alpha and IFN-gamma [38]. Oral administration of high doses of estriol in MS patients, studied by Soldan et al., caused decreased TNFalpha and increased IL-10 and IL-5 secretion from stimulated PBMCs [39]. These data are evidences that favorable change in cytokine balance is an important mechanism of action for female sex hormones.

There are number of publications in the scientific literature about experimental treatments targeting a particular cytokine. All these attempts proved inefficient. This regards

\begin{tabular}{|c|c|}
\hline Cytokine & Studies \\
\hline $\begin{array}{l}\text { TNF-alpha } \\
\text { blokade }\end{array}$ & $\begin{array}{l}\text { van Oosten BW, Barkof F, Truyen L, et al., } 1996 \\
\text { The Lenercept Multiple Sclerosis Study Group and } \\
\text { The University of British Columbia MS/MRI } \\
\text { Analysis Group, } 1999\end{array}$ \\
\hline IL-10 & $\begin{array}{l}\text { Skias DD, Reder AT, } 1995 \\
\text { Wiendl H, Neuhaus O, Kappos L, Hohlfeld R, } 2000\end{array}$ \\
\hline IL-4* & * Bayer company has stopped investigations in phase I \\
\hline TGF-beta & Calabresi PA, Fields NS, Maloni HW, et al., 1998 \\
\hline $\begin{array}{l}\text { Anti-IL-12/23 } \\
\text { p40 }\end{array}$ & $\begin{array}{l}\text { Segal BM, Constantinescu CS, Raychaudhuri A, } \\
\text { Kim L, Fidelus-Gort R, et al., } 2008 \text { Ustekinumab } \\
\text { MS Investigators }\end{array}$ \\
\hline
\end{tabular}


TNF-alpha and IL-12/23 p40 blockade, administration of recombinant IL-10, IL-4, TGF-beta [Table 1]. Neutralization of TNF-alpha in patients with MS led to significant increase in exacerbation frequency and neurological deficit. Treatment with TGF-beta caused renal toxic effect before any beneficial influence on the disease course was observed. Clinical trials with IL-4 and IL-10 were stopped in different phases due to lack of efficacy and recombinant IL-10 administered to animals with EAE even exacerbated the disease. Anti-IL-12/23 p40 did not show difference compared to placebo according the cumulative number of new gadolinium-enhancing cranial magnetic-resonance lesions. The reason for these failures may be searched in the extremely complex cytokine interactions playing role in disease pathogenesis and the delicate and dynamic balance within the cytokine network, necessary for maintaining adequate immune responses. Moreover there are still many unknown details about their local effects in the CNS during different stages of MS.

\section{Conclusion}

The majority of experimental and clinical data indicate that interactions within the cytokine network in MS are extremely complex and divergent. They are highly dynamic and vary through the whole course of the disease and under treatment. Still, there are many gaps and contradictions in this area. The experience from the experimental and clinical trials shows that therapeutic strategies which target restoration of the balance within the cytokine network would be much more beneficial in MS than those, directed towards one singular cytokine signaling. The other main point is the necessity of enlarging the knowledge about immune-CNS interactions and the role of the cytokines in regulation of different subpopulations immune cells throughout the whole course of the disease in order to determine the right target and the right time for given immune therapy.

\section{References}

1. Garg N, Smith TW. 2015. An update on immunopathogenesis, diagnosis, and treatment of multiple sclerosis. Brain Behav 5(9): e00362. doi: $10.1002 /$ brb3.362

2. Buzzard KA, Broadley SA, Butzkueven H. 2012. What do effective treatments for multiple sclerosis tell us about the molecular mechanisms involved in pathogenesis? Int J Mol Sci 13(10): 12665-12709. doi: 10.3390/ijms131012665

3. Imitola J, Chitnis T, Khoury SJ. 2005. Cytokines in multiple sclerosis: from bench to bedside. Pharmacol Ther 106(2): 163-177. doi: 10.1016/j. pharmthera.2004.11.007

4. Imam SA, Guyton MK, Haque A, Vandenbark A, Tyor WR, et al. 2007. Increased calpain correlates with Th1 cytokine profile in PBMCs from MS patients. J Neuroimmunol 190(1-2): 139-145. doi: 10.1016/j. jneuroim.2007.07.016

5. Zozulya AL, Wiendl H. 2008. The role of regulatory $\mathrm{T}$ cells in multiple sclerosis. Nat Clin Pract Neurol 4(7): 384-398. doi: 10.1038/ ncpneuro0832

6. Hedegaard CJ, Krakauer M, Bendtzen K, Lund H, Sellebjerg F, et al. 2008. T helper cell type 1 (Th1), Th2 and Th17 responses to myelin basic protein and disease activity inmultiple sclerosis. Immunology 125(2): 161-169. doi: 10.1111/j.1365-2567.2008.02837.x

7. Lock C, Hermans G, Pedotti R, Brendolan A, Schadt E, et al. 2002. Gene-microarray analysis of multiple sclerosis lesions yields new targets validated in autoimmune encephalomyelitis. Nat Med 8(5): 500-508. doi: $10.1038 / \mathrm{nm} 0502-500$

8. Korn T, Bettelli E, Oukka M, Kuchroo VK. 2009. IL-17 and Th17 cells. Ann Rev Immunol 27: 485-517. doi: 10.1146/annurev. immunol.021908.132710

9. Conti L, De Palma R, Rolla S, Boselli D, Rodolico G, et al. 2012. Th17 cells in multiple sclerosis express higher levels of JAK2, which increases their surface expression of IFN- $\gamma$ R2. J Immunol 188(3): 1011-1018. doi: 10.4049/jimmunol.1004013

10. Amedei A, Prisco D, D'Elios MM. 2012. Multiple Sclerosis: The role of cytokines in pathogenesis and in therapies. Int J Mol Sci 13(10): 1343813460. doi: 10.3390/ijms131013438

11. Bar-Or, Darlington PJ. 2011. The immunology of multiple sclerosis. In: Cohen JA, Rudick RA (eds) Multiple Sclerosis Therapeutics. Cambridge University Press. pp 20-34.

12. Kvarnström M, Ydrefors J, Ekerfelt C, Vrethem M, Ernerudh J. 2013. Longitudinal interferon- $\beta$ effects in multiple sclerosis: differential regulation of IL-10 and IL-17A, while no sustained effects on IFN- $\gamma$, IL-4 or IL-13. J Neurol Sci 325(1-2): 79-85. doi: 10.1016/j. jns.2012.12.001

13. Axtell RC, de Jong BA, Boniface $\mathrm{K}$, van der Voort LF, Bhat $\mathrm{R}$, et al. 2010. T helper type 1 and 17 cells determine efficacy of interferonbeta in multiple sclerosis and experimental encephalomyelitis. Nat Med 16(4): 406-412. doi: 10.1038/nm.2110

14. Alexander JS, Harris MK, Wells SR, Mills G, Chalamidas K, et al. 2010. Alterations in serum MMP-8, MMP-9, IL-12p40 and IL-23 in multiple sclerosis patients treated with interferon-beta1b. Mult Scler 16(7): 801-809. doi: 10.1177/1352458510370791

15. Rudick RA, Ransohoff RM, Peppler R, VanderBrug Medendorp S, Lehmann P, et al. 1996. Interferon beta induces interleukin-10 expression: Relevance to multiple sclerosis. Ann Neurol 40(4): 618-627. doi: 10.1002/ana.410400412

16. Trenova AG, Slavov GS, Manova MG, Kostadinova II. 2014. Cytokines and disability in interferon- $\beta-1 \mathrm{~b}$ treated and untreated women with multiple sclerosis. Arch Med Res 45(6): 495-500. doi: 10.1016/j. arcmed.2014.08.001

17. Pellegrini P, Totaro R, Contasta I, Berghella AM, Russo T, et al. 2004. IFNbeta-1a treatment and reestablishment of Th1 regulation in MS patients: dose effects. Clin Neuropharmacol 27: 258-269.

18. Guerre J, Ford CC. 2011. Glatiramer acetate to treat multiple sclerosis. In: Cohen JA, Rudick RA (eds) Multiple Sclerosis Therapeutics. Cambridge University Press. pp 315-329.

19. Kim HJ, Ifergan I, Antel JP, Seguin R, Duddy M, et al. 2004. Type 2 monocyte and microglia differentiation mediated by glatiramer acetate therapy in patients with multiple sclerosis. J Immunol 172(11): 71447153. doi: 10.4049/jimmunol.172.11.7144

20. Chabot S, Yong FP, Le DM, Metz LM, Myles T, et al. 2002. Cytokine production in $\mathrm{T}$ lymphocyte-microglia interaction is attenuated by glatiramer acetate: a mechanism for therapeutic efficacy in multiple sclerosis. Mult Scler 8(4): 299-306. doi: 10.1191/1352458502ms810oa

21. Aharoni R,Teitelbaum D, Sela M.Arnon R.1998. Bystander suppression of experimental autoimmune encephalomyelitis by $\mathrm{T}$-cell lines and clones of the Th2 type induced by copolymer-1.J Neuroimmunol 91(12): 135-146. doi: 10.1016/S0165-5728(98)00166-0

22. Becher B, Giacomini PS, Pelletier D, McCrea E, Prat A, et al. 1999. Interferon-gamma secretion by peripheral blood T-cell subsets in multiple sclerosis: correlation with disease phase and interferon-beta therapy. Ann Neurol 45(2): 247-250. doi: 10.1002/1531-8249(199902)45:2<247::AID-ANA16>3.0.CO;2-U

23. Rudick RA, Sandrock A. 2004. Natalizumab: alpha 4-integrin antagonist selective adhesion molecule inhibitors for MS. Expert Rev Neurother 4(4): 571-580. doi: 10.1586/14737175.4.4.571

24. Mellergård J, Edström M, Vrethem M, Ernerudh J, Dahle C. 2010. Natalizumab treatment in multiple sclerosis: marked decline of 
chemokines and cytokines in cerebrospinal fluid. Mult Scler 16(2): 208217. doi: $10.1177 / 1352458509355068$

25. O'Connell KE, Mok T, Sweeney B, Ryan AM, Dev KK. 2014. The use of cytokine signature patterns: separating drug naïve, interferon and natalizumab-treated multiple sclerosis patients. Autoimmunity 47(8): 505-511. doi: 10.3109/08916934.2014.930734

26. Cohen JA. 2011. Fingolimod to treat multiple sclerosis. In: Cohen JA, Rudick RA (eds) Multiple sclerosis therapeutics. Cambridge University Press. pp. 370-386.

27. Serpero LD, Filaci G, Parodi A, Battaglia F, Kalli F, et al. 2013. Fingolimod modulates peripheral effector and regulatory $\mathrm{T}$ cells in MS patients. J Neuroimmune Pharmacol 8(5): 1106-1113. doi: 10.1007/ s11481-013-9465-5

28. Achiron A, Falb R, Dolgopiat MD, Magalashvili D, Gurevich M. 2013. Fingolimod induced cytokine profile in cultured monocytes from multiple sclerosis patients. (Meeting Abstracts 1: P05.155) Neurology 12: 80 .

29. Brinkmann V. 2009. FTY720 (fingolimod) in Multiple Sclerosis: therapeutic effects in the immune and the central nervous system. Br J Pharmacol 158(5): 1173-1182. doi: 10.1111/j.1476-5381.2009.00451.x

30. de Jong R, Bezemer AC, Zomerdijk TP, van de Pouw-Kraan T, Ottenhoff TH, et al. 1996. Selective stimulation of T helper 2 cytokine responses by the anti-psoriasis agent monomethylfumarate. Eur J Immunol 26(9): 2067-2074. doi: 10.1002/eji.1830260916

31. Tahvili S, Zandieh B, Amirghofran Z. 2015. The effect of dimethyl fumarate on gene expression and the level of cytokines related to different $\mathrm{T}$ helper cell subsets in peripheral blood mononuclear cells of patients with psoriasis. Int J Dermatol 54(7): e254-260. doi: 10.1111/ ijd.12834

32. Tuohy O, Coles AJ. 2011. Alemtuzumab to treat multiple sclerosis. In: Cohen JA, Rudick RA (eds) Multiple sclerosis therapeutics. Cambridge University Press. pp. 393-398.

33. Yang H, Wang J, Du J, Zhong C, Zhang D, et al. 2010. Structural basis of immunosuppression by the therapeutic antibody daclizumab. Cell Res 20(12): 1361-1371. doi: 10.1038/cr.2010.130

34. Bar-Or A, Pachner A, Menguy-Vacheron F, Kaplan J, Wiendl H. 2014. Teriflunomide and its mechanism of action in multiple sclerosis. Drugs 74(6): 659-674. doi: 10.1007/s40265-014-0212-x

35. Székely JI, Pataki Á. 2012. Effects of vitamin D on immune disorders with special regard to asthma, COPD and autoimmune diseases: a short review. Expert Rev Respir Med 6(6): 683-704. doi: 10.1586/ers.12.57

36. Markovic-Plese S, Singh AK, Singh I. 2008. Therapeutic potential of statins in multiple sclerosis: immune modulation, neuroprotection and neurorepair. Future Neurol 3(2): 153. doi: 10.2217/14796708.3.2.153

37. Coyle PK. 2000. Women's issues. In: Bruks JS, Johnson KP (eds) Multiple sclerosis diagnosis, medical management and rehabilitation. New York: Demos. pp. 505-513.

38. Trenova AG, Slavov GS, Manova MG, Kostadinova II, Vasileva TV. 2013. Female sex hormones and cytokine secretion in women with multiple sclerosis. Neurol Res 35(1): 95-99. doi: 10.1179/1743132812Y.0000000120

39. Soldan SS, Retuerto AIA, Sicotte NL, Voskuhl RR. 2003. Immune modulation in multiple sclerosis patients treated with the pregnancy hormone estriol. J Immunol 171(11): 6267-6274. doi: 10.4049/ jimmunol.171.11.6267 